\title{
JUURNAL.RU
}

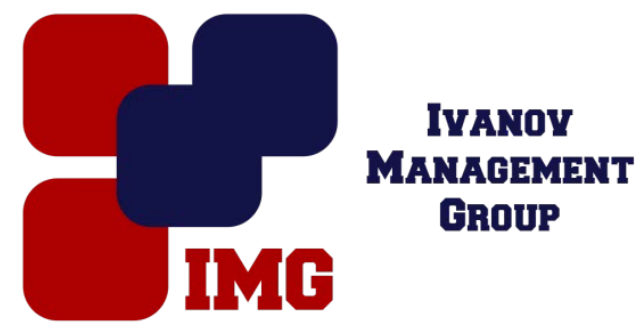

Быковская Е.В.

Тамбовский государственный технический университет

Тамбов, Россия

doi: 10.18411/lj-28-02-2017-2-10

idsp 000001:lj-28-02-2017-2-10

\section{Стратегическая технологическая конкурентоспособность про-мышленных предприятий России: основные составляющие и направления стратегических решений}

\section{Аннотация}

В данной статье дискутируются вопросы, связанные с проблемами повышения эффективности функционирования промышленного предприятия на основе повышения его стратегической технологической конкурентоспособности. Рекомендованы пути повышения эффективности его инновационнотехнологического развития и на этой основе результативности работы этого предприятия. Стратегическая технологическая конкурентоспособность рассмотрена как универсальный механизм, подразумевающий рациональный выбор стратегического управления среди множества альтернатив, согласно их функциональной значимости, при согласованности всех процедур формирования комплекса стратегий.

Ключевые слова: стратегическая конкурентоспособность, промышленное предприятие, конкурентоспособность, эффективный, модель,процессы, инфраструктура.

\section{Abstract}

This article discusses the use of the results, which are very relevant problems in the strategic management of industrial enterprise and factors strategic competitiveness. In the paper recommendations were made on ways to enhance the effectiveness of the current ways to enhance the effectiveness and efficiency of the work of the industrial enterprise on the bases the algorithm of mobilize the reserves of industrial to enhance strategic technological competitiveness, as the universal mechanism meaning a rational choice of reserves among alternatives according to their functional importance is proved, at coherence of all procedures of formation of a complex of strategy. This article focuses on the study of theoretical aspects management of enterprisesand factors strategic competitiveness.

Keywords: strategic competitiveness, strategic management, mobilization , mechanism, reserves, industrial enterprise,competitiveness, effective, , models, processes,, infrastructure. 
Стратегическая конкурентоспособность промышленных предприятий - одна из и активно обсуждаемых тем в современной российской экономической дискуссии. Что, безусловно, вызвано необходимостью преодоления негативных тенденций остановки интеграционных процессов России с Западным мировым экономическим пространством, актуализирующей проблему поиска новых конкурентных преимуществ, прежде всего технологического свойства, которая в условиях кризисного развития, невозможна без долгосрочной инновационнотехнологической модернизации и структурных изменений систем стратегического менеджмента предприятий.

«Концепция долгосрочного социально-экономического развития Российской Федерации до 2020 года» (утв. Распоряжением Правительства РФ от 17 ноября 2008 года №1662), «Стратегия развития малого и среднего предпринимательства в Российской Федерации на период до 2030 года» (утв. от 2 июня 2016г. №1083) определяют приоритетные направления развития экономики России, акцентируя внимание на внедрении инноваций и решению задачи по диверсификации экономики и повышению ее конкурентоспособности[1].

В рамках данных стратегических инициатив существенную роль в обеспечении устойчивого и эффективного функционирования всех субъектов экономических отношений играет соответствие используемых технологий возросшим требованиям по большинству критериев во многом стал определять уровень долгосрочного инновационно-технологического развития производственных систем. В то же время, разделяя мнения российских ученых Вертаковой Ю.В. и Плотникова В.А., стоит отметить, что полноценная реализация инновационно-технологического потенциала промышленных предприятий возможна только при условии адекватного наращивания материальнотехнического и трудового потенциала [2].Изучением влияния разного рода воздействий на состояние предприятия, предпосылки его изменения, в частности предпосылки к формированию стратегической конкурентоспособности, занимались многие отечественные исследователи Басовский Л.Е., Ветрова Е.Н. Винокуров В.А., Волков Д.Л., Герчикова И.Н., Градов А.П., Леонтьев Б.Б, Мельник М.В. Дорожкиной О.К., Коршунова Е.Д., Ильичевой Е.С., Николаева П.В.

Достижение жизнеспособной конкурентоспособности промышленного предприятия невозможно без системных инноваций, отвечающих вызовам окружающей среды, что является залогом их успешного развития в долгосрочном периоде. Особенно болезненным вопросом для российской экономики часто является степень актуальности внедряемых инноваций (используемых инновационных технологий, квалификация персонала, наличие современных высокопроизводительных мощностей и др.)

Опираясь на мнения некоторых исследователей, посвященных данному вопросу, мы предлагаем выделить следующие цели инновационного развития индустриального сектора России:

- внедрение на предприятии комплексного высокотехнологичного оборудования, являющегося основой обеспечения устойчивости, прогрессивности, конкурентоспособности его производственносбытовой деятельности и возможностей опережающего развития; 
- интеграции предприятия с передовыми научно-техническими комплексами с целью реализации прогрессивных технологий, производстве высокотехнологичной продукции, финансовыми институтами, способными обеспечить инвестирование технологического развития предприятия[3 ];

- осуществление различных форм интеграции промышленного предприятия с организациями, промышленными предприятиями своей отрасли, научно-исследовательскими организациями, образовательными учреждениями способными повысить уровень его инновационного развития[4 ].

Из чего следует вывод, что, только при комплексном изменении всех процессов производственно-хозяйственной деятельности, реализуемых на предприятии, возможно достижение целей его долгосрочного инновационного развития.

Расширяя выше представленные определения путем добавления большего обзора возможностей повышения конкурентоспособности, используя кардинально другой подход изыскания ее источников, с целью большей проработки детализации решений анализируемых в исследовании проблем стратегической конкурентоспособности предприятия, мы предлагаем ввести в научный оборот понятие стратегической технологической конкурентоспособности промышленного предприятия, далее СТК.

Автор определяет СТК, как обобщенную характеристику существующего и потенциально возможного уровня развития предприятия в конкурентной среде за счет выделения неиспользуемых или недоиспользуемых групп резервов(можно назвать их «спящими») и возможностей их мобилизации в стратегической перспективе. Что предлагается осуществить с помощью внедрения комплекса предложенных автором методик мобилизации внутрихозяйственных резервов для долгосрочного развития промышленного предприятия на основе таких факторов, как: 1) преодоления выявленной разницы между фактическим и предельно возможным результатом производственного процесса, уровнем использования технического оснащения производственных систем, 2) преодоления выявленной разницы между существующим и максимально возможным эффектом деятельности персонала предприятия, обслуживающего технологический и управленческо-технологический процессы ,3) положительным эффектом от изменения разницы между потенциально- оптимальным количеством инфраструктурных связей предприятия и их фактическим количеством, в том числе логистических, учет которых позволит повысить устойчивость долгосрочного развития предприятий в условиях нестабильной внешней среды.

Обеспечение СТК позволяет предприятию производить и реализовывать конкурентоспособную продукцию. В свою очередь, наличие у предприятия СТК и конкурентоспособность продукции позволят сделать вывод о наличии у предприятия конкурентоспособности вообще. Объединение направлений повышения конкурентоспособной продукции и ТКС представляет собой основную часть конкурентоспособности предприятия.

Под стратегической устойчивостью конкурентных промышленного предприятия может, по нашему мнению, способность конкурентных преимуществ обеспечивать стратегическую технологическую конкурентоспособность производственной системы при 
изменяющихся воздействиях ее внешней и внутренней среды.

Рассмотрим схематически представленный процесс создания стратегической технологической конкурентоспособности промышленного предприятия поэлементно, как целую совокупность составляющих его частей (Рис.1).

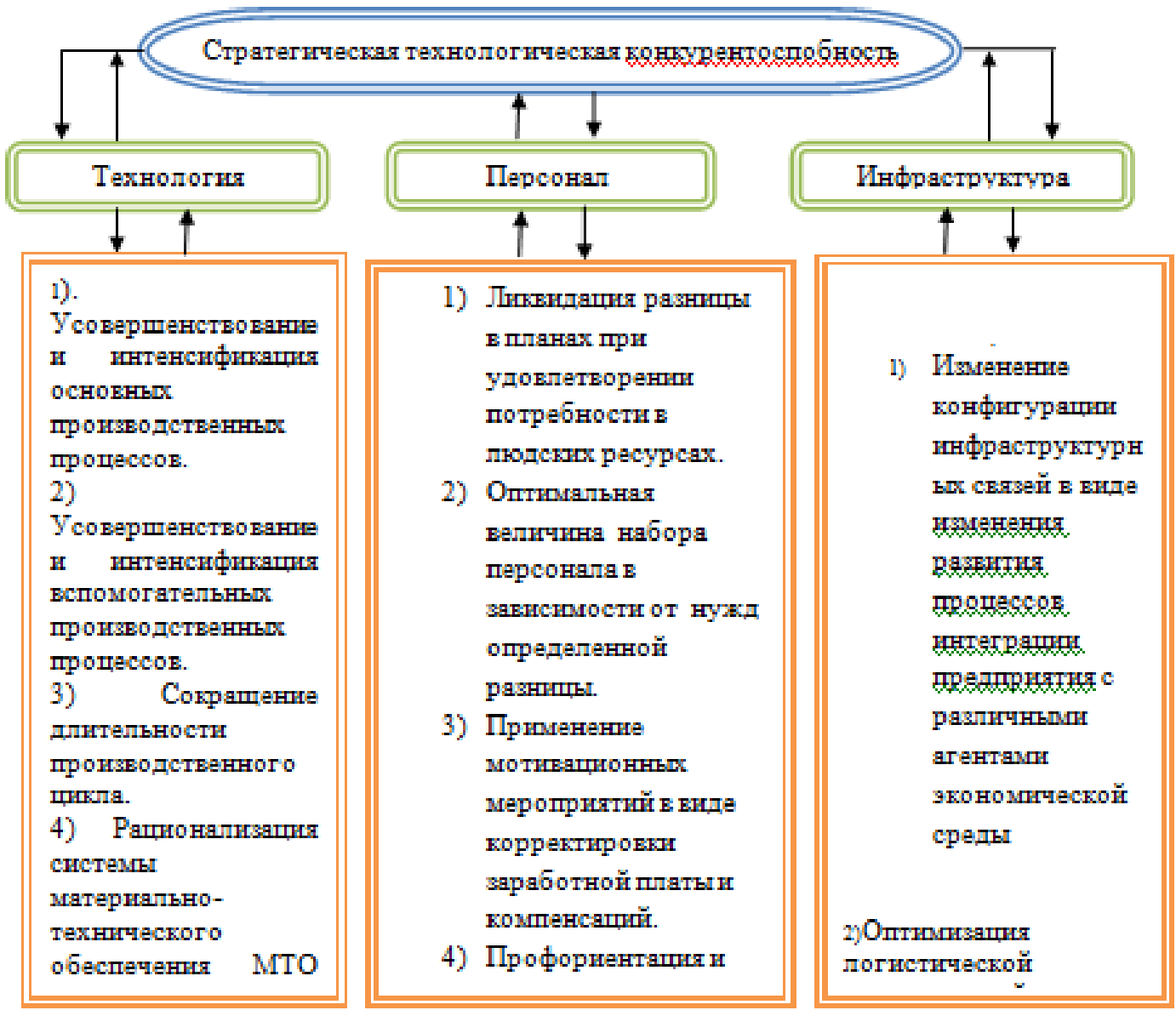

Рисунок 1 - Составляющие формирования стратегической технологической конкурентоспособности

В рамках модернизации промышленного предприятия в долгосрочном периоде повышение его стратегической технологической конкурентоспособности возможно за счет решения следующих задач:

- за счет реорганизации производственных процессов и освоения новых технологий;

- за счет повышения уровня развития научно-исследовательских и опытно-конструкторских работ;

- за счет повышения качества производимой продукции ;

- повышения за счет изменений реорганизации мотивационно контрольных аспектов функциональной деятельности персонала предприятия;

- за счет повышения качества обучения и привлечения кадров, в особенности, производственного персонала и менеджмента в производственной системе предприятия;

- за счет изменения подходов к управлению предприятием, в частности, оценки текущего уровня и перспектив развития 
предприятия с точки конфигурации инфраструктурных связей, т.е в виде изменения развития процессов интеграции предприятия с различными агентами экономической среды[6].

В качестве основы для формирования СТК промышленного предприятия, как ключевого инновационного фактора его долгосрочного развития, автор предлагает использовать, следующиеосновными составляющие:

1) инновационные технологии основных и вспомогательных процессов производства продукции;

2) инновационные технологии управления персоналом, обслуживающем производство продукции, прежде всего технологический процесс;

3) инновационные технологии инфраструктурных связей предприятия.

Детализируя представленную на рисунке 1 схему, необходимо заметить, что под инновационно-конкурентными технологиями процессов понимаются новые методологические подходы организации производственного процесса на предприятии, включающие в себя инновационные технологии использования экономических ресурсов всех видов, инновационные технологии средств труда, инновационные интеллектуальные технологии.

Для осуществления подобной рациональной реорганизации производственных процессов и, соответственно, повышения СТК, у многих промышленных предприятий России, вопреки устойчиво сложившемуся мнению последнего времени, есть внушительный ряд предпосылок.

Рассмотрим потенциал роста СТК промышленных предприятий и производственных комплексов ЦФО РФ на примере характеристик предприятий индустриального сектора Тамбовской области, некоторые из которых являлись объектами данного исследования.

В целом промышленный комплекс Тамбовской области в 2013-2016 годах показал определенный рост, однако, как показывают данные статистической отчетности, сохраняются некоторые диспропорции в темпах развития, как отдельных предприятий, так и отдельных отраслях.

Таким образом, выше представленные выкладки позволяют сделать вывод, обобщенно представленный в таблице 1 , что тенденции развития промышленных предприятий Тамбовской области в 2012-2016 годах демонстрируют достаточность их экономического потенциала и потенциала окружающей среды для данного экспериментального исследования механизма повышения стратегической технологической конкурентоспособности на основе мобилизации их внутрихозяйственных резервов.

При оценке возможностей формирования и реализации СТК промышленных предприятий одного региона -Тамбовской области, основное внимание было сфокусировано на следующих моментах:

- состав задач, решенных разработчиками при обосновании повышения СТК предприятий; 
- востребованный потенциальный инструментарий для решения.

Для наглядного отражения полученных нами результатов представим их в табличной форме (табл.1).

Таблииа 1

Состав задач, решенных при формировании и реализации СТК промышленных предприятий ЦФО РФ (Тамбовской области)

\begin{tabular}{|c|c|c|c|c|c|c|c|}
\hline $\begin{array}{c}\text { Промышленные предприятия } \\
\text { Тамбовской области }\end{array}$ & \multicolumn{7}{|c|}{ Состав задач } \\
\hline 1 & 2 & 3 & 4 & 5 & 6 & 7 & 8 \\
\hline ПАО « Пигмент» & - & - & - & - & - & - & - \\
\hline ПАО «Тамбовмаш & - & - & - & + & - & + & + \\
\hline $\begin{array}{c}\text { Территориально распределенный } \\
\text { комплекс ОАО «Биохим» }\end{array}$ & + & - & + & + & - & - & + \\
\hline ОАО» «Кондитерская фирма «ТАКФ» & - & + & - & + & + & - & + \\
\hline Тамбовский завод «Комсомолец» им» & + & - & - & - & - & + & + \\
\hline Тамбовский завод «Полимермаш» & - & + & + & + & - & - & + \\
\hline Фабрика «Тамбовчанка» & - & + & + & - & + & + & - \\
\hline $\begin{array}{c}\text { TВЕС Тулиновский } \\
\text { приборостроительный завод }\end{array}$ & - & - & - & - & - & - & - \\
\hline Тамбовский завод «Октябрь» & + & - & - & - & + & + & + \\
\hline Тамбовгальванотехника им Лившица & - & - & - & - & - & - & - \\
\hline Тамбовский завод «Аппарат» & - & + & - & - & + & - & - \\
\hline ЭЗЛМК Тамбовский & - & - & - & - & + & - & + \\
\hline Тамбовский завод «Ревтруд» & - & + & - & - & + & - & - \\
\hline Мичуринский завод «Прогресс» & - & - & - & - & - & - & + \\
\hline Мичуринский завод поршневых колец & - & - & - & - & - & - & + \\
\hline $\begin{array}{c}\text { ООО «Бондарский сыродельный } \\
\text { завод» }\end{array}$ & - & - & + & - & + & - & - \\
\hline $\begin{array}{c}\text { Коршуновский Литейно- } \\
\text { механический завод }\end{array}$ & - & - & - & - & + & - & + \\
\hline $\begin{array}{c}\text { ООО «СОСНОВСКИЙ } \\
\text { ДЕРЕВООБРАБАТЫВАЮЩИЙ } \\
\text { ЗАВОД» } \\
\end{array}$ & - & - & - & - & - & + & + \\
\hline $\begin{array}{c}\text { ОАО «Тамбовский завод } \\
\text { «Электроприбор» }\end{array}$ & - & - & + & - & + & - & + \\
\hline ОАО «Корпорация «Росхимзащита» & + & - & - & + & - & + & - \\
\hline
\end{tabular}

Условные обозначения: 2 - выявление и учет «узких мест в производственных процессах; 3 - оценка на региональном рынке; 4 - оценка стратегической конкурентов позиции продукции предприятия стратегической конкурентов позиции продукции предприятия на национальном рынке; 5 определение и оценка рисков инвестиционной деятельности; 6 - обоснование миссии; 7 - балансировка экономического и технологического параметров развития предприятия; 8 - установление состава форм и инструментов стратегического управления развития предприятия .

Таким образом, сформированная стратегическая технологическая конкурентоспособность предприятия создает новые конкурентные преимущества для его долгосрочного развития в виде, в первую очередь, экономии ресурсов, сохранности информации, высокой интеллектуализации персонала, 
коммерциализации инноваций, увеличении вновь добавленной стоимости, и повышение конкурентоспособности предприятия в целом.

Резюмируя итоги исследования необходимо отметить, что совершенствование процесса стратегического управления промышленных предприятий России должно осуществляться в направлении их долгосрочной инновационно-технологической модернизации на основе повышения стратегической технологической конкурентоспособности, что в свою очередь должно сопровождаться сопутствующими процессами изменения законодательной, методологической, организационной, институциональной основы функционирования национальной экономической системы.

\section{Литература}

1. «Концепция долгосрочного социально-экономического развития Российской Федерации до 2020 года» (утв. Распоряжением Прави-тельства РФ от 17 ноября 2008 года №1662

2. Плотников В.А., Вертакова Ю.В. Российская промышленность: текущее состояние и перспективы развития// Экономика и управле-ние. 2014. №5(103). С. 39-44.

3. Клочкова Е.Н., Кузнецов В.И., Платонова Т.Е.. Экономика пред-приятия. М.: Юрайт, 2014. 448.

4. Година О.В. Формирование портфеля стратегических альтернатив развития инновационно-ориентированного предприятия// Успехи современной науки. 2015. №5. C. 41-48.

5. Коршунова Е.Д., Николаев П.В. Повышение технологической кон-курентоспособности промышленного предприятия на основе ис-пользования технологий инвестирования инновационным оборудо-ванием / Е.Д. Коршунова, П.В. Николаев // Вестник МГТУ «Стан-кин», 2011. - №3(15) С. 178-181.

6. Верещагина Л.С. Развитие организационно-экономического меха-низма промышленного предприятия на основе исследования резер-вов// Микроэкономика. 2010. №6. C. 63-68.

7. Карпова Н.П. Стратегическая логистика снабжения/ Карпова Н.П.- М.: «Креативная экономика», 2014.-168c.

8. Козлов Д.В. Инновации как ключевой фактор повышения конку-рентоспособности предприятий// Молодой ученый.- 2011. - №9.-С.94-97

9. Фатхудтинов Р.А Производственный менеджмент. М.: Книга по Требованию, 2011.496c. 